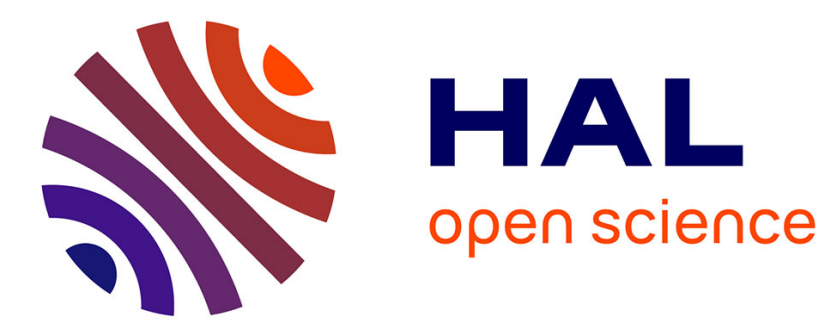

\title{
Ultrasound and microbubble-assisted gene delivery: recent advances and ongoing challenges
}

\author{
Anthony Delalande, Michiel Postema, Nathalie Mignet, Patrick Midoux, \\ Chantal Pichon
}

\section{- To cite this version:}

Anthony Delalande, Michiel Postema, Nathalie Mignet, Patrick Midoux, Chantal Pichon. Ultrasound and microbubble-assisted gene delivery: recent advances and ongoing challenges. Therapeutic Delivery, 2012, 3 (10), pp.1199-1215. 10.4155/TDE.12.100 . hal-03193228

\section{HAL Id: hal-03193228 \\ https://hal.science/hal-03193228}

Submitted on 15 Apr 2021

HAL is a multi-disciplinary open access archive for the deposit and dissemination of scientific research documents, whether they are published or not. The documents may come from teaching and research institutions in France or abroad, or from public or private research centers.
L'archive ouverte pluridisciplinaire HAL, est destinée au dépôt et à la diffusion de documents scientifiques de niveau recherche, publiés ou non, émanant des établissements d'enseignement et de recherche français ou étrangers, des laboratoires publics ou privés. 


\section{Ultrasound and microbubble-assisted gene delivery: recent}

\section{2 advances and ongoing challenges}

4 Anthony Delalande, Michiel Postema, Nathalie Mignet, Patrick Midoux, Chantal Pichon 5

\section{Abstract}

7 Having first been developed for ultrasound imaging, microbubbles are nowadays proposed as

8 tools for ultrasound-assisted gene delivery, too. Their behaviour during ultrasound exposure

9 causes transient membrane permeability of surrounding cells, facilitating targeted local

10 delivery. The increased cell uptake of extracellular compounds by ultrasound in the presence

11 of microbubbles is attributed to a phenomenon called sonoporation. Sonoporation has been

12 successfully applied to deliver nucleic acids in vitro and in vivo in a variety of therapeutic

13 applications. However, the biological and physical mechanisms of sonoporation are still not

14 fully understood.

15 In this review, we discuss recent data concerning microbubble-cell interactions leading to

16 sonoporation and we report on the progress on ultrasound-assisted therapeutic gene delivery

17 in different organs. In addition, we outline ongoing challenges of this novel delivery method

18 for its clinical use. 


\section{$21 \quad$ Key terms}

Sonoporation: phenomenon by which ultrasonic stimulation transiently alters the

24 permeability of cell plasma membrane, thereby allowing the uptake of extracellular 25 molecules. This phenomenon is amplified by the presence of microbubbles.

26 Microbubbles: encapsulated gas bubbles with diameters up to 10 micrometres. Firstly 27 developed as contrast agents for ultrasonic medical imaging, they might be used as carrier 28 vehicles to deliver drugs or genes, aided by sonoporation.

29 Acoustic cavitation: formation, oscillation, and collapse of bubbles under sonication.

30 Ultrasonic and microbubbles-assisted gene delivery: external-triggered method of plasmid 31 DNA transfer based on sonoporation. 


\section{Introduction}

Gene therapy aims at introducing genetic material into mammalian cells to cure genetic deficiencies and a large variety of acquired diseases. So far, viruses have demonstrated the feasibility of gene therapy and remain the best vehicles to introduce genes into cells. But severe fatal adverse events of viral vectors including acute immune response and insertion mutagenesis observed in gene therapy clinical trials have raised serious safety concerns about their use [1,2].

Therefore, clinical developments still require the use of alternative approaches of high safety, low immunogenicity and easy manufacture. Moreover, the size limitation capacity, weakness of cell targeting and manufacturing issues has boosted efforts to search for non-viral options. During the last decade, many efforts have been carried out to design synthetic or chemical gene delivery systems that incorporate viral-like features required to transfect efficiently cells [3-5]. The final goal of these systems is to deliver a plasmid encoding a therapeutic protein into target cells upon systemic administration. This challenge could be achieved if several extracellular barriers are overcome to reach the target cells where the therapeutic gene has to be efficiently expressed. Tremendous efforts have been made to improve the efficacy of different types of "synthetic viruses" and elegant strategies have been proposed for that as reported in recent reviews [6-8].

However, achieving optimal targeted gene delivery systems based on chemical compounds is still highly challenging. Narrow therapeutic indices and lack of selectivity towards target tissues have been observed. The absence of specificity that causes severe toxicity often hampers the efficacy at the target site. In this respect, innovative delivery strategies that could selectively target tissues of interest are ongoing both in experimental and in clinical research. It is obvious that designing an efficient targeted delivery strategy is the next step to further improve delivery systems and to reduce side effects. Among the delivery 
systems found are several physical methods starting from a simple naked DNA injection to much more sophisticated systems such as electroporation and ultrasound-mediated delivery (USMD).

Ultrasound is used for diagnostic clinical applications and for treatment either by itself or in combination with drugs $[9,10]$. Among the variety of imaging modalities, ultrasonic imaging is a well-established and reliable technique for diagnosis. The development of real-time imaging has allowed for visualizing a variety of anatomical structures noninvasively. These last years, therapeutic applications of ultrasound have gained new interests thanks to the exploitation of ultrasound for delivery. The effect of ultrasound on biological systems was already reported in 1927 [11], but it took until 1987 until the first study on ultrasound-assisted gene delivery was published [12]. Depending on the acoustic settings, ultrasound can induce either thermal or non-thermal effects, each having its own applications. The thermal effects are obtained using high ultrasound intensities and are due to the absorption of acoustic energy by tissue leading to heating. This property of ultrasound is used in techniques like high-intensity focused ultrasound (HIFU) for focussed ultrasound surgery (FUS) or physiotherapy by ultrasound. One of the first applications of HIFU was sonothrombolysis for ischemic stroke treatment. It has been shown that the introduction of microbubbles in the blood pool could act as cavitation nuclei and decrease the energy threshold for thrombolysis by a third [13]. The thermal effects can present a risk on sonicated tissues; the World Federation for Ultrasound in Medicine and Biology Temperature state that an elevation of $1.5^{\circ} \mathrm{C}$ is considered safe while an elevation of $4-5^{\circ} \mathrm{C}$ during 5 minutes is potentially dangerous [14]. The non-thermal effects are obtained using lower ultrasound intensities. The main non-thermal effects are inertial cavitation and acoustic streaming. These effects can induce some benefits such as tissue healing or ultrasound-mediated drug or gene delivery. 

The use of ultrasound as an external trigger is one approach that has proven to be 85 effective for drug delivery. The drugs to be delivered can be chemotherapeutic agents for 86 cancer therapy applications or oligonucleotides for gene therapy applications. Ultrasound 87 enables to control both the drug release and the release location by use of ultrasound [15-21]. 


\section{Ultrasound}

Ultrasound is a form of mechanical vibration of matter with a frequency beyond human audible range, i.e., above $20 \mathrm{kHz}$. The speed of sound is dependent of the medium: roughly $340 \mathrm{~m} / \mathrm{sec}$ in air, $1480 \mathrm{~m} / \mathrm{sec}$ in pure water, $1550 \mathrm{~m} / \mathrm{sec}$ in soft tissue and $3700 \mathrm{~m} / \mathrm{sec}$ in bone $[22,23]$. The particle excursion in a sound wave is related to the instantaneous local pressure through the wave equation [24]. The wave is damped with propagation distance due to tissue absorption and geometric effects [24]. This behaviour induces mechanical effects in the medium which are amplified when inertial cavitation occurs. Inertial cavitation is the process of formation and subsequent collapse of bubbles driven by an acoustic field [25]. Acoustic cavitation takes place when the peak-negative pressure amplitude of ultrasound waves at given frequency exceeds the so-called cavitation threshold [24]. If so-called cavitation nuclei brought by impurities in the medium are present, the cavitation threshold is lowered. Preformed microbubbles serve as cavitation nuclei and are exploited in ultrasonic contrast imaging. These so-called ultrasound contrast agents consist of micron-size gas-filled bubbles (typical diameter ranged is $1-10 \mu \mathrm{m}$ ) encapsulated by an elastic shell. They oscillate during ultrasound exposure (stable cavitation) and demonstrate highly nonlinear behaviour that ameliorates their detection. Oscillating microbubbles introduced in the blood stream produce a sound field themselves and therefore indicate regions of tissue perfusion [26,27]. The acoustic backscattering of these agents is several orders of magnitude higher than the surrounding tissues.

It has been proposed that microbubble activity plays a key role in therapeutic applications [9]. Stable cavitation refers to the (nonviolent) regime of microbubble oscillation, whereas inertial or transient cavitation corresponds to microbubble oscillation with increasingly large amplitudes until collapsing violently [28]. In the nonviolent regime, fluid streaming around oscillating microbubbles may create enough shears to (transiently) open up 
114 cell membranes. Furthermore, the microbubbles themselves may interact with, or even 115 translate through cell membranes [29]. In the inertial regime, jets from collapsing 116 microbubbles have been observed to penetrate cells, inducing permanent damage [30]. 


\section{Mechanisms of ultrasound-mediated delivery (USMD)}

Several studies have been conducted these last years to delineate mechanisms involved in USMD [31-35]. Many experimental data have shown that exposure to ultrasound increases the cellular uptake of extracellular molecules. The uptake is significantly higher if an ultrasound contrast agent is added [36,37]. However, it is under discussion exactly how cells that are subjected to ultrasound internalize extracellular compounds, and which cellular responses they evoke.

Sonoporation is the ultrasound-assisted transient permeabilization of cell membranes. This permeabilization allows for the transfer of molecules between the intra- and extracellular medium. Several sonoporation mechanisms have been identified. The main hypotheses of microbubble interaction with cells are the push and pull mechanisms, microjetting, micro-streaming, and, more recently, translation of microbubbles through cells [29]. It

130 has been proposed that the attraction of oscillating microbubbles by cells is caused by sonophores, tiny cavities inside cell membranes [38].All these sonoporation mechanisms have been demonstrated with the aid of high-speed photography. These mechanisms of membrane poration have been summarized in Figure 1 (inset).

If a microbubble is touching a cell, the microbubble oscillations induce a cellular massage [39]. This cellular massage mechanically stimulates the plasma membrane. It has

136 been hypothesised, that during the expansion phase of the microbubble the plasma membrane 137 is pushed inward and that during the compression phase the microbubble pulls the plasma 138 membrane outward [31].Repeated push and pull on the plasma membrane creates weaknesses 139 that might lead to the formation of a pore. In a high-mechanical-index regime, the formation

140 of a microjet can occur. A microjet is a fluid protrusion towards a surface during inertial 141 bubble collapse. Jetting has been observed through cells with laser-generated cavities [30]. 142 However, this mechanism induces high cell toxicity. Several studies conducted in silico, in 
143 vitro, and in cellulo suggest that microbubble jetting behaviour is less likely to be the

144 dominant sonoporation mechanism [40].

145 Another possibility of pore formation mechanism is the rupture of the cell membrane by the

146 streaming flow created by an oscillating microbubble. Indeed, when an oscillating

147 microbubble is attached to a cell membrane the shear forces induced are strong enough to

148 deform and rupture the cell membrane locally [41,42].

149 Recently a hypothesis has been presented for cell membrane pore formation after 150 ultrasonic stimulation in the absence of microbubbles[38], which involves bilayer sonophores.

151 In electron microscopy images of fish skin after sonication[43], holes in the inter-cellular 152 space were observed, attributed to cavitation between membrane layers (plasma membrane, 153 nucleus and mitochondria). The hypothesis states that cavitation nuclei could be present 154 between the membrane layers inducing a membrane swelling during the rarefaction phase of 155 ultrasound. This deformation could lead to the formation of a pore. This is consistent with the 156 theory on ultrasound-stimulated liposome membranes[21].

A new mechanism has been discovered recently by observing microbubble 158 interactions with cells at a low mechanical index (MI). It appears that the microbubbles can 159 enter into the cell straight through the membrane. This translation phenomenon has been 160 proven by the use of fluorescent labelled microbubbles[44]. The fluorescence of the

161 microbubble has been found in the cell after the observation of a translating microbubble. The 162 microbubble loses (part of) its shell during translation and dissolves quickly after entering the 163 cell. This new mechanism may trigger new drug delivery strategies.

\section{Size of the pore}

The formation of a pore during sonication is well-established. Several groups have detected the presence of pores on cell membranes by electron microscopy after sonoporation

$167[34,45,46]$. Mehier-Humbertet al. were the first to study the poration size. They showed the 168 presence of $100 \mathrm{~nm}$-sized pores in the cell membrane by electron microscopy. The use of 
169 fluorescence nanospheres of specific sizes allowing for the measuring of the uptake in

170 MATBIII cells by flow cytometry. They concluded that sonoporation induced a poration of

171 the cell membrane facilitating the transfer of 75 -nm-sized spheres. However this study has

172 been done with a specific type of microbubble making the comparison with other 173 studiesdifficult. More recently, Zhou et al. used an electro-diffusion model to measure the 174 size of the pore during sonoporation [47]. This technique based on transmembrane current 175 measurements by voltage clamp [48] permitted to evaluate the size of the pore in live during 176 sonoporation, the pore size measured was $110 \pm 40 \mathrm{~nm}$. This value is consistent with the results 177 obtained by electron microscopy. Although several studies have shown the presence of a pore 178 after sonication, we still do not know if these pores are responsible of the drug entry. The cell 179 membrane permeabilization and viability is highly dependent on the ultrasound parameters 180 [49]. Juffermans et al. have reviewed the cellular effects of ultrasound [50]. Ultrasound has 181 been shown to induce a transient intracellular calcium entrance only in the presence of 182 microbubbles [48,51-56]. This calcium entrance could promote pore closure [48] and 183 endocytosis [57,58]. The closure time of the pore has been estimated at 5 seconds after 184 ultrasound stimulation [34,47]. It has been reported that sonoporation induces the production 185 of hydrogen peroxide $\left(\mathrm{H}_{2} \mathrm{O}_{2}\right)$, which plays an important role in calcium entrance and 186 consequently in pore formation [59]. This production of $\mathrm{H}_{2} \mathrm{O}_{2}$ has been shown by others and 187 is thought to be related to inertial cavitation [55,60,61]. A hyperpolarisation of sonicated cells 188 has been recorded on different cellular types (Xenopus oocyte, MDA-MB-231, NIH3T3, $189 \mathrm{H} 9 \mathrm{c} 2)$ in the presence of microbubbles[48,62,63] and in absence of microbubbles [55]. This 190 phenomenon is directly related to a mechanical stress of the cell membrane. A similar 191 hyperpolarization was observed applying a mechanical pressure on the membrane using a 192 glass probe [64]. The hyperpolarization is attributed to the opening of the $\mathrm{BK}_{\mathrm{Ca}}$ channels 193 [62,63]. The hyperpolarization and the calcium signaling could increase the uptake of 
macromolecules by endocytosis or macropinocytosis.Moreover, we have found sonoporation

195 can also induce an outward transport of small intracellular molecules that likely due to membrane destabilization [33]. The permeabilization engenders a transient release of small molecules such as enhanced green fluorescent protein (eGFP) from the cytosol of HeLa cells stably expressing eGFP gene while preserving cell viability. These results reinforce the theory that the pore formation is a transient mechanism. Active sonoporation is not likely to be the 200 only mechanism for increased uptake, because endocytosis mechanism might also be involved [56]. It is still not clear if the type of mechanism(s) involved could be both dependent on the microbubble chemical composition and on the type of tissue.

\section{Importance of the size of the cargo and endocytosis}

The presence of a pore during sonoporation allows for the passive transfer of molecules between the extracellular and the intracellular medium. Hence, the size of the pore limits the size of the cargo to deliver. The use of fluororescent dextran has shown a completely different localization profile depending of the molecular size of dextran after sonoporation [56]. A small dextran molecule $(3 \mathrm{kDa})$ would be localized and diffused inside the cytoplasm and in the nucleus, a medium-sized dextran molecule $(70 \mathrm{kDa})$ would be

210 present in the cytoplasma only, and large dextran molecule (150 and $500 \mathrm{kDa})$ would be 211 found aspatchy structures in the cytoplasm. Endocytosis plays an important role in the USMD 212 process, indeed it has been shown that endocytosis inhibitors could decrease the drug delivery 213 efficiency by sonoporation [55,56]. In these studies, the authors presented a colocalization of 214 the drug to deliver and the coating endosomes protein, clathrin. Meijering et al. used dextrans 215 as reporter cargos. They observed that the inhibition of endocytosis pathways (clathrin, 216 caveolin and macropinocytosis) inhibited the delivery. The size of pDNA corresponds to the 217 MDa weight range (a $6 \mathrm{~kb}$ plasmid average molecular weight would be $3.6 \mathrm{MDa}$ ). The 218 important size of plasmid DNA (even folded) implies that the entrance of the plasmid in the 
cell through a pore is not the main event. Paula et al.have observed a colocalization between

220 pDNA and clathrin suggesting that pDNA can be routed to the clathrin-mediated endocytosis

machinery [56]. The link between endocytosis and drug delivery by sonoporation seems to be

wellestablished.Yet, when the plasmids reach the endocytosis machinery, they have to escape

from the endosomes in order to avoid lysosomal degradation and be available for the import

to the nucleus for gene expression. To our knowledge, the trafficking of the plasmid DNA

after sonoporation is still ill known. The mechanisms of gene uptake after sonoporation are summarized in Figure 1.

The gene transfer efficiency is dependent on acoustic pressure, frequency, duty cycle,

type used $[33,49,65]$. The use of luciferase reporter plasmid has permitted to identify the optimal parameters for an efficient genedeliveryin vitro. Withour experimental setup,the optimal parameters found were $1 \mathrm{MHz}, 150 \mathrm{kPa}, 40 \%$ duty cycle (ratio of run time to total cycle time), $60 \mathrm{sec}$ of sonication time and $0.3 \%(\mathrm{v}: \mathrm{v})$ of microbubble. Under these conditions, less than $10 \%$ of cytotoxicity has been measured (Delalande et al., unpublished results).

\section{Microbubbles features for improved efficiency in gene delivery}

Most microbubbles used as commercial ultrasound contrast agents have a biodegradable shell composed of phospholipids and a heavy gas core, to prevent them from rapid dissolution. Their diameters are typically below $10 \mu \mathrm{m}$, to allow them to pass through 239 the capillary system.

The usual production techniques are based on emulsion by shaking or sonication.

241 They induce a wide size distribution of the microbubble size. Moreover, the use of ultrasound 242 in this technique generates high pressures and temperatures which could lead to a degradation 243 of the shell components. Getting a narrow distribution of the microbubble population with 
244 these methods is challenging and requires the use of centrifugation and filtration steps.

245 However other microbubble production methods using microfluidic T-junction chambers or 246 coaxial electrohydrodynamic atomisation are under development and could be able to produce 247 microbubbles of a specific diameter size [66]. While the size distributions of microbubbles used is appropriate for imaging, they are 249 nevertheless too wide and present a polydispersity unsuitable for therapeutic applications 250 [67], for extensive reviews see [21,36,37,68]. The thickness and the elasticity of the shell 251 determine microbubbles stability. A microbubble having a very soft shell would be disrupted at small pressure variations. However, a microbubble with a very hard shell would not be able to oscillate. The most elastic shells are made of phospholipids while the stiffer shells are made of polymers or proteins. To reduce the softness of the phospholipid-based microbubble shell, polymers are usually added. Custom microbubbles are mainly made with classical phospholipids, perfluorocarbon gas and pegylated lipids [69-72]. The presence of the polyethylene glycol (PEG) on the lipid plays the role of emulsifying agent [73]. The development of acoustically active microbubbles has been optimized (for a review [68]) but 259 efforts have been mainly focused to get microbubbles with an optimized acoustic response. 260 These microbubbles are highly echogenic but again they are made with classical 261 phospholipids without any specific feature. Recently, more complexes molecular architecture 262 of liposome-based microbubble have been described: liposomes bubbles consisting of PEG263 modified liposomes that encapsulate perfluoropropane gas enclosed in PEG-lipid micelles $264[74,75]$ and a hybrid particle made with microbubble loaded with liposomes that are made of 265 thousands of small unilamellar biotinylated liposomes attached via avidin molecule to 266 biotinylated microbubble[76]. Of note, the big size, the complexity of architecture and the use 267 of biotin and avidin in those systems are not convenient for in vivo use. 
To achieve improvements in sonoporation, the development of new microbubbles

269 able to reach specifically the target and deliver the nucleic acid locally is needed. Targeted 270 microbubbles like Target-Ready Micromarker ${ }^{\circledR}$ (VisualSonics ${ }^{\mathrm{TM}}$ ) can be found on the 271 market, the targeting consists of the conjugation of antibodies linked to the microbubble by 272 biotin-streptavidin interaction (Figure 2). Targeted-microbubbles with antibodies can interact 273 with a specific antigen present on a cell membrane allowing the binding of the targeted 274 microbubble even when they are in flow [77]. For example, microbubbles can be targeted to 275 the P-selectin to analyze the endothelium inflammation [78] or to the scVEGF have been 276 developed to analyze tumor angiogenesis [79]. These microbubbles are mainly used in molecular imaging, their development was only based on the acoustic properties and they are not able to carry nucleic acids.

Two main strategies have been proposed to prepare microbubbles able to bind nucleic acids: (i) the use of cationic lipids (DOPE, DOTAP) in the composition of the microbubble shell allowing electrostatic interactions between the nucleic acid and the microbubble, (ii) Compacting the nucleic acid using polymers or liposomes linked to the microbubble by biotin-streptavidin interaction (Figure 2). The use of cationic microbubbles to 284 directly complex pDNAis being more and more reported [80-84]. In these studies, gas-filled cationic liposomes were made with neutral classical (DMPC or DSPC) and cationic lipids as (1,2-distearoyl-3-trimethylammoniumpropane). There are different manners to couple liposomes or polymers on microbubbles. Amongst them are the deposition of single [85]or ii) 288 multi-layers [86] of cationic polymer on the microbubble shell to complex pDNA and a 289 covalent linking of nucleic acids-nanoparticle carriers [87]. These strategies offer the 290 possibility of having the DNA complexes and the microbubble at the same location and likely 291 at the same time. As an example, Sirsiet al. have coupled PEI on the surface of lipid-based 292 microbubbles via polyethylene glycol lipid [88]. 
Despite a good acoustic response of these microbubbles, the level of in vivo gene transfer 294 obtained with them was rather low may be due to different limitations of the use of large bubbles size (limited or no extravasation). These last years, Maruyama and colleagues have developed bubble liposomes (BLs) which have smaller size $(<1 \mu \mathrm{m})$ than conventional microbubbles. These structures combine the liposomes features and the acoustic activity of microbubbles. They are composed of DSPC and DSPE-PEG2000-OMe phospholipids filled with perfluoropropane gas [89]. BLs were efficient to deliver gene in vitro and in vivo. The optimal parameters used for in vitro delivery are $2 \mathrm{MHz}$ ultrasound frequency, duty cycle of $50 \%, 2.5 \mathrm{~W} / \mathrm{cm}^{2}$ of intensity and $10 \mathrm{sec}$ of exposure time. Whilst for in vivo (solid or ascites tumors), the best parameters are $1 \mathrm{MHz}$ ultrasound frequency, duty cycle of $50 \%, 1 \mathrm{~W} / \mathrm{cm}^{2}$ of intensity and 1 to 2 min of exposure time [90-93]. Taking into account the particular features of these BLs (small size, gas particles embedded in liposomes). It will be of interest to know 305 if the different proposed events leading to pore formation can be applied for such structures 306 (figure 1).

\section{Applications of US-mediated delivery for in vivo gene delivery}

The potentiality of US-mediated delivery (USMD) applied for gene transfer is attested by the growing number of related publications for both in vitro and in vivo use [94-96]. The

311 minimal invasiveness and the high targeting capacity of USMD render the technique potential 312 for clinical transfer. Efficient gene transfer by sonoporation has been obtained when 313 transmitted ultrasound frequencies used are close to those used clinically and extend from 0.5 314 to $4 \mathrm{MHz}$. Molecules having variable molecular weights ranging from plasmids [35], 315 oligonucleotide [97] to radioactive tracers [39] were successfully incorporated into cells by 316 sonoporation. In the first studies, pDNA were used alone in presence of ultrasound without 317 microbubbles. Significant results have been obtained in vitro as well as in vivo with focused 
ultrasound [98-100]. Microbbubles have been added to enhance the sonoporation efficiency.

319 However, the level of gene expression is still not higher than that obtained with chemical vectors even though it can be 1 or 2 orders of magnitude more than the level obtained with pDNA alone $[94,95]$. One of the main difficulties in the field of ultrasound-assisted gene delivery is the lack of homogeneity in sonication set-ups and acoustic conditions used

323 yielding comparisons rather hard to make. Indeed, ultrasound parameters applied are variable

324 in terms of frequency (from 1 to $4 \mathrm{MHz}$ ), of acoustic power (from to 0.5 to $5 \mathrm{~W} / \mathrm{cm}^{2}$ ) of pulse mode (from $10 \%$ to continuous wave) and of stimulation time (from $10 \mathrm{sec}$ to $30 \mathrm{~min}$ ). The association of ultrasound with gas microbubbles is necessary to get an optimal transfection even though application of ultrasound alone induces a weak molecule transfer into cells 328 [46].The majority of studies conducted on USMD has been performed in vitro with a variety 329 of cell types including primary cells [95]. The main conclusion that can be drawn is the necessity to optimize ultrasound parameters, microbubble and pDNA concentrations for every cell types. Concerning the type of microbubbles, one critical feature is their stability 332 considering the positive correlation between microbubble lifetime and the sonoporation 333 efficiency [101]. Moreover, the stability of gas microbubbles is dependent on both its shell 334 and gas composition $[65,101]$.

These last years, more and more studies report the successful use of ultrasound-

336 enhanced gene transfer in vivo both with reporter and therapeutic genes. In the next step, we 337 will focus more on advances in USMD for in vivo gene delivery applications and especially 338 for cardiovascular applications following systemic injection. Then we will describe studies 339 relative to USMD application following local injection of pDNA in musculoskeletal tissues. 340 Next, some recent significant data obtained by combining USMD and others delivery systems 341 will be reported. 


\section{Cardiovascular applications}

It is not surprising that one of the first application of ultrasound and microbubble for gene delivery concerns cardiovascular imaging system. Since, imaging of cardiovascular system has been highly improved by contrast enhanced ultrasound thanks to the wide development of microbubbles in order to detect cardiovascular perfusion pathologies. Combination of the visualization of heart structures and gene delivery has been obtained by exploiting USMD in rats. Commercial and custom microbubbles were tested to deliver pDNA encoding luciferase in the left ventricle [102]. Triggered $1.3 \mathrm{MHz}$ insonation applied every 4 heartbeat gave higher gene expression compared to insonation under continuous mode. The organ specificity is validated by the restriction of gene expression mainly to the heart. The absence of toxicity and the safety of the method (no significant modification in host genes regulation) permit a repeated treatment enhancing the duration of gene expression [103]. Taniyama and colleagues have reported a gene therapy trial on rat restenosis after angioplasty model [46]. A long-term benefit effect of angioplasty is limited by restenosis phenomenon occurring in $40 \%$ of patients. This process is produced by an abnormal smooth muscle cell proliferation of intima. The delivery of pDNA encoding p53 anti-oncogene protein in the presence of ultrasound $\left(2.5 \mathrm{~W} / \mathrm{cm}^{2}\right)$ and Optison ${ }^{\mathrm{TM}}$ microbubbles has produced an overexpression of p53 in smooth muscle cells leading to an inhibition of intima cells proliferation on rat carotid artery [46].

USMD applications for therapeutic angiogenesis have been widely investigated in 363 myocardial infarction and in hind limb ischemia models in rodents. In a rabbit hind limb 364 ischemic model, the transfer of pDNA encoding the Hepatocyte Growth Factor (HGF) by 365 ultrasound associated with Optison ${ }^{\mathrm{TM}}$ microbubbles has allowed to get a better angiogenesis compared to transfer of pDNA alone or pDNA with ultrasound [46]. In a rat model of 367 infarction, a treatment combining ultrasound and microbubbles with pDNA encoding the 
HGF reduced significantly the scar and left ventricle weight with an increased number of

369 capillaries compared to control groups comprising treatment with pDNA alone or pDNA with

370 ultrasound and untreated rats [104]. More recently, the efficiency of USMD was investigated

371 in a severe chronic ischemia model [105]. The treatment consisting of VEGF-165 gene

372 delivery was performed 2 weeks after the induction of unilateral hind limb ischemia in rats.

373 Upon intravenous injection, of $500 \mu \mathrm{g}$ pDNA encoding VEGF-165 coupled to these

374 microbubbles were injected intravenously (IV), the muscle blood flow assed by contrast-

375 enhanced ultrasound and the vessel density investigated by fluorescent microangiography

376 were improved in ischemic adductor muscles exposed to ultrasound and with minimal

377 changes in control groups. The expression of VEGF persisted for 4 weeks. Even though the

378 amount of pDNA used was quite high, this study demonstrates the potentiality of USMD for

379 gene delivery since it was expected that microbubbles would have a low transit through

380 ischemic skeletal muscle. The same research group has compared the efficacy of the VEGF

381 gene delivery by USMD after IV injection to intramuscular (IM) injection [106]. They found

382 that the best increase of the microvascular blood flow and volume was obtained with USMD

383 despite the low transfection efficiency. This superiority could be attributed to the wider

384 localization of transgene expression in the vascular endothelium of capillaries and arterioles

385 of ischemic adductor muscle whilst it was mainly localized to perivascular regions and

386 myocytes of injection site area after IM injection. Along the same line, Fuji and colleagues

387 have delivered VEGF gene or Stem Cell Factor gene, another angiogenic gene, to the murine

388 myocardium seven days after coronary artery ligation [107]. DNA delivery was performed in

389 presence of Definity ${ }^{\circledR}$ (Lantheus medical imaging) MB and US at $8 \mathrm{MHz}$ with a mechanical

390 index of 1.6 directed to the heart during 20 min with an intermittent mode of 1 burst every

391500 msec. Two weeks post-treatment, an improved capillary and arterial density, myocardial

392 function and infarct morphometry was obtained in treated animals. The cardiac repair proved 
by echocardiography and myocardial perfusion, was further improved when multiple

394 treatments were performed (1, 3 or 6 at 2 days interval) [108].

induce a sufficient gene delivery. The injection of pDNA encoding the luciferase combined

with cationic lipid microbubbles by intra-muscular (IM), intra-venous (IV) or intra-arterial

398 (IA) routes and with an insonation of rat hind limb skeletal muscles has also been assessed

399 [82]. Luciferase activity detected in limb muscles following IA injection was similar to that

400 obtained following IM injection and was 200-fold greater than achieved after IV

401 administration. Overall, these studies demonstrate the strength of this method for future

402 cardiovascular disease therapies.

\section{Bone, muscle, intervertebral discs and tendon}

404 Osteoinduction is required in the field of orthopedics when there are high bone 405 defects caused by fracture, joint related surgery and congenital anomalies. The improved 406 knowledge of genes involved in bone formation has facilitated the development of new 407 therapeutic applications for bone repair and bone regeneration [109]. Amongst them, Bone 408 Morphogenetic Proteins (BMPs) are known for their ability to induce bone formation. BMP11 409 transfection has been successfully achieved in canine teeth in vivo by sonoporation, this 410 transfection has allowed a reparative dentin formation [110]. In 2007, a pilot study made by 411 Gazit's group showed that sonoporation is able to induce bone formation in hindlimb muscle

412 of mice [111]. Acoustic parameters consisting of $1 \mathrm{MHz}$ ultrasoundat5 $\mathrm{W} / \mathrm{cm}^{2}, 50 \%$ duty 413 cycle and 10 min exposure time combined with injection of $50 \mu \mathrm{g}$ pDNA encoding rhBMP-9 414 mixed to 5\% Optison ${ }^{\mathrm{TM}}$ gave the highest efficiency for ectopic bone formation. It is 415 interesting to note that compared to electroporation, the volume of bone formed using 416 sonoporation in muscles was lower but more dense. This difference in the volume density 417 obtained by sonoporation could be attributed to the therapeutic benefit effect of ultrasound. 
Indeed, it is known that low-intensity pulsed ultrasound (LIPUS) has a positive effect on bone regeneration [112].

Another study related to the BMP-2 gene transfer by repeated sonoporation treatments confirmed the promise of USMD for bone induction [113]. BMP-2 has the ability to induce the differentiation of non-osteogenic cells into osteoblasts [114]. Sonoporation has been done at $1 \mathrm{MHz}, 4 \mathrm{~W} / \mathrm{cm}^{2}$ and a $50 \%$ duty cycle in presence of $75 \mu \mathrm{g}$ pDNA and SonoVue ${ }^{\circledR}$ microbubbles. X-ray imaging, histochemical analysis and biochemical evaluation were performed to assess the osteo-induction. Data show that when the transcutaneous sonoporationwas repeated 7 times with a 24-hour interval, a cartilage and immature bone were detected in the treated area after 14 days. On day 21, radiographies show denser opacities than on day14 and muscle fibers revealed the presence of bone matrix with bone marrow and many osteoblasts concomitantly with high level of biochemical markers (calcium and alkaline phosphatase).

These last decades, the aging population led to an upsurge of age-related pathologies as degenerative diseases. In many spinal disorders, degeneration of the intervertebral discs is an underlying etiology that causes pain and morbidity $[115,116]$. Nishida et al. have been the

434 first who reported the application of USMD on intervertebral discs [117]. They have mixed microbubbles with pDNA encoding the GFP and the firefly luciferase before local injection

436 into rat coccygeal intervertebral discs followed by ultrasound exposure on the surface of 437 injected discs. Ultrasound application induced an improvement of the gene transfer efficiency 438 by 11 -fold over pDNA alone. The method has been also successful to transfer siRNA in 439 intervertebral discs [118]. Local injection of siRNA (20pmol) mixed with Optison ${ }^{\mathrm{TM}}$ followed 440 by ultrasound exposure $\left(1 \mathrm{MHz}, 2 \mathrm{~W} / \mathrm{cm}^{2}\right.$ and $60 \mathrm{sec}$ ultrasound exposure time) has resulted 441 in long-term expression lasting up to 24 weeks. This expression led to long-term down442 regulation of exogenous reporter gene in rat discs in vivo. This unusual long period of RNA 
443 inhibition in intervertebral disc in vivo may be due to the long quiescent state of highly 444 differentiated disc cells.

445 We have also observed such lasting expression in Achilles tendons. Tendons are also 446 composed of tenocytes that divide very slowly. Our recent data show remarkably that it is 447 possible to get an efficient localized gene expression in Achilles tendons which is sustained 448 up to 100 days by using ultrasound and BR14 lipid shelled microbubbles[119,120]. 449 Optimized gene transfer was obtained with $1 \mathrm{MHz}$ ultrasound frequency, $200 \mathrm{kPa}$ and $40 \%$ 450 duty cycle in the presence of $10 \mu \mathrm{gpDNA}$ and $5 \times 10^{5} \mathrm{BR} 14$ microbubbles. The level of gene 451 transfer was 130 -fold more efficient than that obtained with naked pDNA. Note that this 452 sustained gene expression is relied on the presence of microbubbles since no effect of 453 ultrasound or microbubble alone was obtained. The level of gene expression obtained here 454 was as good as with adenoviral vectors in tendons highlighting the potential of this system 455 [121]. Most importantly, this approach has permitted the restoration of fibromodulin gene 456 expression fibromodulin $\mathrm{KO}$ mice. Ultrastructural analysis of these tendons revealed that 457 collagen fibrils diameter distribution and circularity were similar that of wild type mice 458 indicating that the fibromodulin expression was enough to restore the collagen fibrils 459 phenotype one week post-transfection.

460 The effectiveness of this method in tendons could be due to the presence of standing wave 461 which is produced when the reflected ultrasound beam from any sort of interface and the 462 progressive ultrasound beam merge together [150]. Tendons being structures close to bone, a 463 standing wave can be created. Therefore, the exact acoustic power that exactly applied to 464 tendons is hard to know because of the standing wave. This could explain the need of long 465 exposure time as $10 \mathrm{~min}$ to achieve high and sustained tendon gene transfer. 
The USMD feasibility has also been examined for cancer gene therapy. Several studies have been performed to evaluate its efficiency on different cancer cells in vitro (for a review see $[94,95,122])$. Intra-tumoral injection of anti-tumor gene or systemic injection gene delivery followed by a percutaneous application of ultrasound on the tumor region has also been reported [122-125]. One recent example concerns the production of interleukin (IL)-12 protein through the injection of pDNA encoding IL-12 either in skeletal muscular fibers or directly delivered to the targeted tumor or tissue by blood vessels close to it [92]. Intra-tumor administration is still the best route giving efficient gene expression and in most cases repeated administration is required to reduce the tumor growth [126-128]. One explanation could be the high dilution of pDNA after injection in the blood pool.

From these studies, one can conclude that efficient acoustic conditions have been obtained with $1 \mathrm{MHz}$ with an output of 2 to $5 \mathrm{~W} / \mathrm{cm}^{2}$ and 20 to $50 \%$ duty cycle with various exposure times that seems to be dependent on the microbubbles used. In most case, in vivo ultrasoundmediated gene therapy resulted in a 55\% cure rate in tumor-bearing animals. This efficacy is comparable to that obtained with an electrotransfer-based approach but with the benefit of the non-invasiveness of the method.

\section{Combination of USMD and other delivery systems}

USMD has also been used in combination with viral or non-viral vectors in order to enhance gene transfer efficiency. The benefit of this combination is the potentiality to enhance the delivery of the gene in a vicinity of ultrasound and microbubble action.

489 An improvement of viral adenoviral gene transfer has been reported in rat cardiomyocytes in 490 vivo following heart exposure with ultrasound. The treatment was consisting of viral particles 491 injection into apical myocardium of the ventricle and application of $1 \mathrm{MHz}$ ultrasound, 1.5 $492 \mathrm{~W} / \mathrm{cm}^{2}$, continuous wave during $5 \mathrm{~min}$ before and after injection. This condition has enhanced 
the percentage of transfected myocytes from $1.7 \%$ to $13.2 \%[129]$. Another study reported by

494 Horward et al .concerns the encapsulation of adenoviral vectors inside Imagent@ microbubble 495 injected via tail vein [130]. This has enhanced the specificity of the transgene expression in 496 vitro as well as in vivo to the target organs. Their results elegantly demonstrate that when 497 Imagent ${ }^{\circledR}$ microbubbles were reconstituted in presence of adenoviral vectors, it allows 498 preventing their destruction from complement system activation. The improved transduction 499 in the targeted area was generated upon application of acoustic pressures less than 500kPa. 500 More recently, a combination of adenoviral vector (Ad5 serotype) that encodes for MDR-1 501 associated with Albumin-coated perfluoropropane gas microbubbles filled with fluorocarbon 502 has been found to be efficient to transduce rabbit bone marrow mononuclear cells [131]. The 503 improvement of gene expression observed was almost 3-fold (8.5\% with Ad-5 alone versus $50424.5 \%$ with Ad-5 combined with ultrasound and microbubble) with no alteration of the cell 505 viability. The presence of microbubbles did not enhance significantly the gene transfer efficiency compared to ultrasound alone. This might be due to the stability of the microbubble used. Indeed, it has been found that microbubble stability is one of the requirements for 508 optimal sonoporation efficiency. A comparison between Optison ${ }^{\mathrm{TM}}$, SonoVue ${ }^{\circledR}$ and 509 Sonazoid® has shown that stability, more than size and shell, crucially influenced gene therapy (Alter et al., 2009). Optison ${ }^{\mathrm{TM}}$ and Sonazoid ${ }^{\circledR}$ have a similar efficiency in heart that 511 is superior to that of SonoVue®, this latter being less stable. Combining viral vectors with ultrasound and microbubble gives the possibility to 513 downscale by at least one order of magnitude the amount of viral vectors required for an 514 efficient transduction as shown by Muller et al.[132]. In their work, AAV vectors encapsulated in liposomes-based bubbles upon systemic injected have been efficiently targeted into rat hearts upon ultrasound application which is a noninvasive technique in 
contrast to direct intramyocardial or intracoronary. Of note, all studies have demonstrated that

518 no relevant cardiac adverse events occurred following these treatments [133,134].

useful tool for gene delivery into eye[135], are hard to scale up rendering their use for clinical applications limited [136]. The easy accessibility of ocular surface has opened the use of physical method as electroporation to transfer therapeutically genes [137]. USMD can deliver pDNA into retinal ganglion cells safely and effectively in vitro and in vivo. An enhancement of rAAV transduction into retinal ganglion cells of rats was obtained after intravitreal injection. Recombinant AAV serotype 2 infection combined with ultrasound has led to an efficient, stable and safe transfection of the retina [138]. Gene transfer in retina using USMD has been tested in vitro and in vivo. The rAAV serotype 2 was chosen to assess the feasibility, efficiency, and safety of the transfection of rAAV2 into RGCs in vivo by USMD. When examining the retinal flat mounts, data prove that eGFP expression in the AAV2-eGFP and USMD-treated group was the strongest and the number of transfected retinal ganglion cells was higher (19.48\% versus $3.23 \%)$ compared to control groups. Gene transfer into retinal ganglion cells has a tremendous application because of its potentiality to treat glaucomatous optic neuroprotection by preventing apoptosis [139].

A combination of USMD and chemical vectors has been also proposed in different recent studies. Sonoporation has been found to enhance the efficiency of polyethyleneimine (PEI) in vitro [140-142]; as well as in vivo[143,144]. Deshpande and Prausnitz have reported

537 that the combination of ultrasound and PEI has a synergistic effect to increase pDNA 538 transfection efficiency[141]. They examined the influence of ultrasound and PEI:pDNA complexation on transfection of human aortic smooth muscle cells and human prostatic 540 carcinoma DU145 cells with GFP and luciferase reporter genes. Ultrasound stimulation 541 improves the transfection by up to 18 -fold relative to naked DNA and by 90 -fold when this 
542 latter is complexed with PEI. The combination of ultrasound and Optison ${ }^{\mathrm{TM}}$ microbubbles 543 with PEI/pDNA complexes increased the transfection up to 200-fold resulting in the 544 transfection of $34 \%$ of the cells. Qiu and colleagues have assessed the correlation between 545 acoustic cavitation and sonoporation in ultrasound-mediated gene transfection with PEI in 546 vitro [142]. The study was done on MCF-7 cells and with $1 \mathrm{MHz}$ ultrasound frequency in the 547 presence of microbubbles. Data indicate that the transfection efficiency initially increased 548 linearly with the acoustic cavitation, reaching saturation when the acoustic cavitation is too 549 high. There was a high correlation between the measured acoustic cavitation, the sonoporation 550 pore size assessed by electron microscopy, and the cell viability. Xenariou et al. have 551 evaluated the effect of sonoporation on gene delivery mediated by a cationic lipid GL67

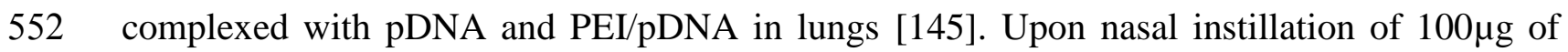
553 pDNA in mice, their chests were exposed with ultrasound. Despite the possible ultrasound 554 waves attenuation when travelling through air, sonoporation $\left(1 \mathrm{MHz}, 3 \mathrm{~W} / \mathrm{cm}^{2}, 20 \%\right.$ duty cycle and 20 min of exposure time) increases the transfer of naked pDNA when mixed with 556 microbubbles (Optison ${ }^{\mathrm{TM}}$ ), but no enhancement of the transfection efficiency of GL67/pDNA 557 or PEI/pDNA occurred. Moreover, lung hemorrhages were observed with the optimal 558 acoustic parameters. These data suggest the necessity of optimizing the acoustic conditions 559 and the type of microbubbles used to prevent ultrasound bio-effects without altering the 560 benefit on the gene delivery. The main aim will be to develop original microbubbles for safe, 561 non-invasive and target controlled drug delivery by sonoporation in order to enhance the 562 delivery of their payload at a specific location.

\section{5. Considerations and future perspectives}

Exciting results from recent clinical trials demonstrate without doubt the promise of gene therapy. The advances made shows that the field is now surely moving from the 
conceptual technology to more and more clinical translational. The majority of these advances

568 have been obtained with viral vectors. Therefore, there is still room for non viral methods to

569 be developed since they are more secure in terms of safety. But, improving their efficacy is

570 mandatory for a widespread use. The combination of the ultrasound trigger effect with

571 targeted gas microbubbles as drug/gene carrier holds great promise by offering a double

572 targeting controlling both gene release and gene transfer location [15-21]. The non-

573 invasiveness of this system renders it superior to other physical methods as electroporation.

574 However, some challenges must be overcome to ensure its efficiency and data consistency.

575 Below are some points that could be considered:

- Rigorous characterization of acoustic fields and description of the experimental configurations: One has noticed that there is lack of consistency regarding the ultrasound exposure configurations in many studies. Researchers in the field are encouraged to describe the set-up used and to make such measurements. This will make the comparison between different studies easier and will help to the identification of critical points which in turn will 581 allow to fast forwarding the technology. Recently, the Safety Committee of the British

582 Medical Ultrasound Society has published a useful set of recommendations that could be easily followed [146].

- Combining a judicious choice of microbubbles composition and plasmid DNA sequence with regard to gene delivery in a specific cell type: It is know well admitted that the gene transfer efficacy of any non viral system is highly dependent on the cell or organ type.

587 So far in the case of USMD, cationic microbubbles that complex pDNA did not improve the efficiency as much as expected. This could be due to the fact that if an endocytosis process occurs during sonoporation, internalized pDNA has to overcome cellular barriers similar to those encountered by chemical vectors [147]. Therefore, pDNA escape from endosomes and 
591 its diffusion and entry inside the nucleus must be improved. This could be tackled by fine

592 tuning microbubble composition and reducing their size.

593 The composition of pDNA backbone and its length has to be chosen with care depending on

594 the type of gene expression needed (transient or long-term expression). Today, enough 595 experience has been gained in the field of gene delivery to define pDNA constructs that bear 596 specific sequences facilitating nuclear import and long-term gene expression [147-149].

597 - An improved knowledge of microbubble-cell interactions and how they affect the cell 598 and the impact on the gene delivery is still required to exploit this method in a safe and 599 efficient way. A better understanding of underlying mechanisms that are induced at the 600 plasma membrane and inside the cells during the sonoporation would establish a rational 601 determination of ultrasound exposure conditions. Compilation of new observations and 602 identifying molecular signaling mechanisms induced by sonoporation could help to optimize 603 rationally this delivery method.

604 - The development of ultrasound platform that allow monitoring in real time a 605 concomitant imagine of gene delivery could be useful. In this case, it would be necessary to 606 design original microbubbles that could serve as platforms to develop targeted microbubble 607 for both imaging and delivery applications.

608

609 


\section{Executive summary:}

611 Gene therapy potentiality to cure inherited and acquired diseases is well established. Non-

612 viral methods offer a good alternative for gene therapy due to safety reasons. Unlike other

613 physical delivery methods, ultrasound-mediated delivery allows to combine the possibility of

614 reaching deeper organs with a non-invasive manner and to restrict the delivery at a specific

615 area.

616 Sonoporation mechanism

617 - Sonoporation uses ultrasound activation of microbubbles to increase the permeability of

618 plasma membrane of cells.

619 -Gas microbubbles oscillations under ultrasound activation induce membrane alteration

620 including formation of transient pores and endocytosis process.

621 Applications for gene delivery

622 - Ultrasound and microbubbles-assisted delivery can be exploited to efficiently deliver genes

623 in vitro as well as in vivo in several organs after systemic or local administration. The optimal

624 ultrasound parameters used are highly dependent on the microbubble, the type of cell or the 625 tissue.

626 - In most case, efficient acoustic conditions have been obtained with $1 \mathrm{MHz}$ with an output 627 ranging from 2 to $5 \mathrm{~W} / \mathrm{cm}^{2}$ and from 20 to $50 \%$ duty cycle with various exposure times that 628 seems to be dependent on the type of microbubbles used and insonified tissues.

629 - Ultrasound and microbubble-assisted delivery combined with viral or chemical vectors has a 630 synergetic effect to improve the gene delivery in the vicinity of ultrasound and microbubble 631 action.

$632 \quad$ Future challenges

633 -Designing targeted microbubbles that are able to carry the gene of interest could also reduce 634 the amount of nucleic acid needed. 
635 - More knowledge on the impact of microbubbles-cell interactions and the intracellular 636 routing of microbubbles and pDNA has to be gained to fully exploit this methodology. This 637 will allow to fine tune microbubbles composition and to design adequate equipment 638 according to the target organs and to translate the technology for clinical use.

639 


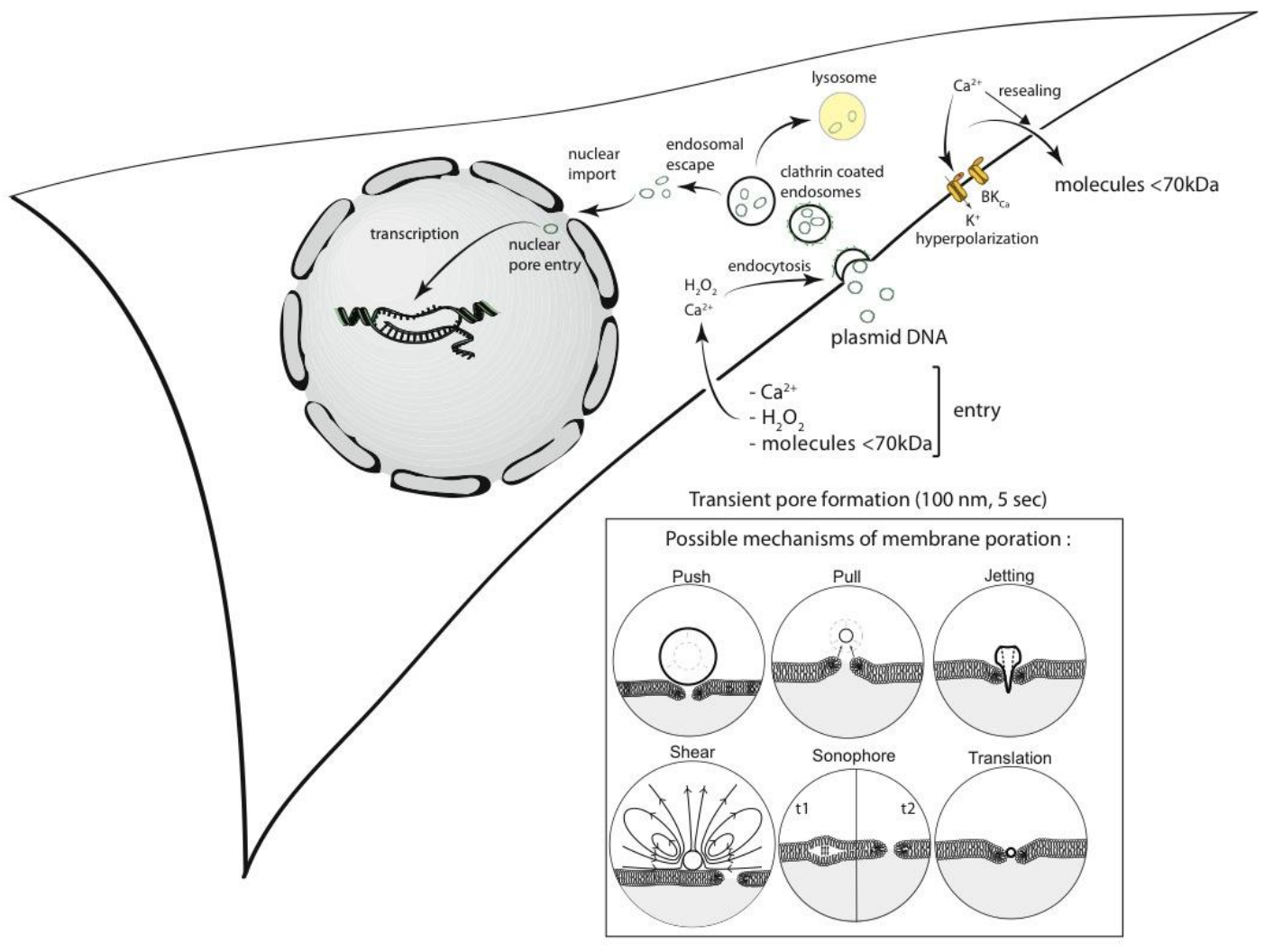

Figure 1.Schematic description of mechanisms occurring during sonoporation.

644 Upon ultrasound exposure, the microbubble is interacting with cell membrane leading to the 645 formation of a pore. Here are summarized the six possible mechanisms of membrane poration 646 (inset): the pushing or pulling of the membrane by a microbubble; the microbubble jetting 647 toward the cell membrane; the mechanical shear force; the sonophore formation within the 648 membrane layers and the translation of a microbubble to a cell. The membrane poration is a 649 transient mechanism (5 sec) leading to the passive entry/exit of ions and small molecules. 650 Calcium and $\mathrm{H}_{2} \mathrm{O}_{2}$ entry enhances the endocytosis process allowing extracellular molecule uptake. Hyperpolarization produced by $\mathrm{BK}_{\mathrm{Ca}}$ channels activation caused by calcium entry could positively impact the endocytosis. The pDNA was found mainly uptaken via clathrin653 mediated pathway. The pDNA has to escape from endosomes to avoid lysosomes and it must 654 be imported into the nucleus for its expression. 


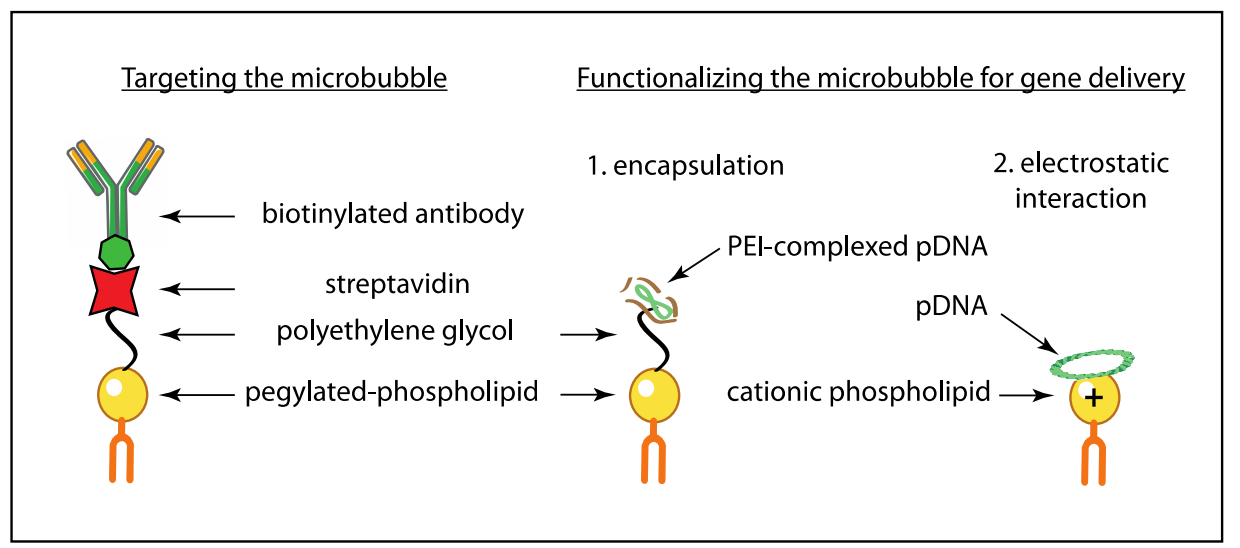

656

657

658

659

660

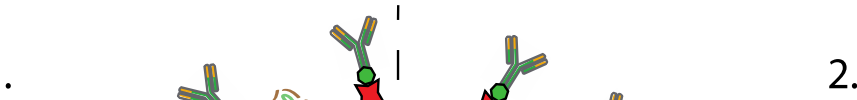

2.

Figure 2. Representation of two possible strategies for microbubble targeting and functionalization for gene delivery.

Specific target

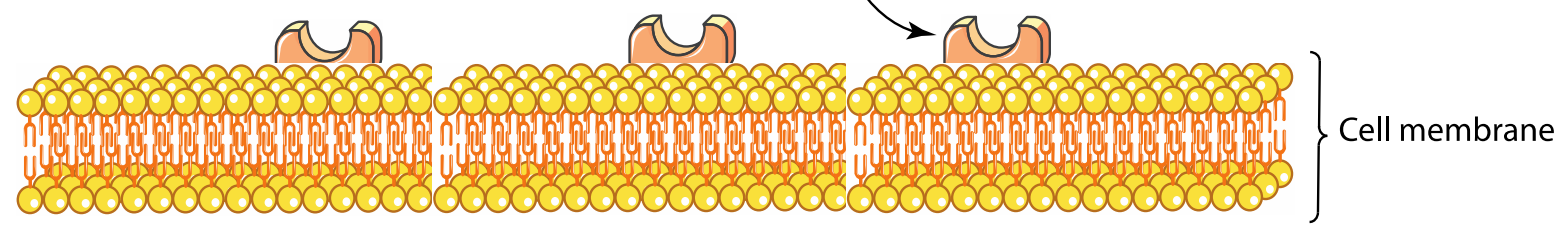




\section{References}

663 Papers of special note have been highlighted as:

$664 *$ of interest

** of considerable interest

1. Raper SE, Chirmule N, Lee FS et al. Fatal systemic inflammatory response syndrome

2. Hacein-Bey-Abina S, von Kalle $\mathrm{C}$, Schmidt $\mathrm{M}$ et al. A serious adverse event after successful gene therapy for X-linked severe combined immunodeficiency. $N$ Engl $J$ Med, 348(3), 255-256 (2003).

3. Mahato RI. Non-viral peptide-based approaches to gene delivery. Journal of drug targeting, 7(4), 249-268 (1999).

4. Midoux P, Pichon C, Yaouanc JJ, Jaffres PA. Chemical vectors for gene delivery: a current review on polymers, peptides and lipids containing histidine or imidazole as nucleic acids carriers. British journal of pharmacology, 157(2), 166-178 (2009).

5. Wagner E, Ogris M, Zauner W. Polylysine-based transfection systems utilizing receptor-mediated delivery. Adv Drug Deliv Rev, 30(1-3), 97-113 (1998).

6. Glover DJ. Artificial Viruses: Exploiting Viral Trafficking for Therapeutics. Infect Disord Drug Targets, (2011).

7. Miyata K, Nishiyama N, Kataoka K. Rational design of smart supramolecular assemblies for gene delivery: chemical challenges in the creation of artificial viruses. Chem Soc Rev, 41(7), 2562-2574 (2012).

8. Wagner E. Polymers for siRNA Delivery: Inspired by Viruses to be Targeted, Dynamic, and Precise. Acc Chem Res, (2011).

9. Mitragotri S. Healing sound: the use of ultrasound in drug delivery and other therapeutic applications. Nat Rev Drug Discov, 4(3), 255-260 (2005).

10. Lindner JR. Molecular imaging with contrast ultrasound and targeted microbubbles. $J$ Nucl Cardiol, 11(2), 215-221 (2004).

11. Wood RW, Loomis AL. The physical and biological effects of high-frequency soundwaves of great intensity. Philos. Mag., 4(22), 417-436 (1927).

12. Fechheimer M, Boylan JF, Parker S, Sisken JE, Patel GL, Zimmer SG. Transfection of mammalian cells with plasmid DNA by scrape loading and sonication loading. Proc Natl Acad Sci U S A, 84(23), 8463-8467 (1987).

13. Tachibana K, Tachibana S. Albumin microbubble echo-contrast material as an enhancer for ultrasound accelerated thrombolysis. Circulation, 92(5), 1148-1150 (1995).

14. Barnett SB, Ter Haar GR, Ziskin MC, Rott HD, Duck FA, Maeda K. International recommendations and guidelines for the safe use of diagnostic ultrasound in medicine. Ultrasound Med. Biol., 26(3), 355-366 (2000).

15. Kinoshita M, McDannold N, Jolesz FA, Hynynen K. Targeted delivery of antibodies through the blood-brain barrier by MRI-guided focused ultrasound. Biochem Biophys Res Commun, 340(4), 1085-1090 (2006).

16. Frenkel V. Ultrasound mediated delivery of drugs and genes to solid tumors. $A d v$ Drug Deliv Rev, 60(10), 1193-1208 (2008).

17. Kost J, Leong K, Langer R. Ultrasound-enhanced polymer degradation and release of incorporated substances. Proc Natl Acad Sci U S A, 86(20), 7663-7666 (1989).

18. O'Neill BE, Li KC. Augmentation of targeted delivery with pulsed high intensity focused ultrasound. Int J Hyperthermia, 24(6), 506-520 (2008). 
19. Rapoport N, Gao Z, Kennedy A. Multifunctional nanoparticles for combining ultrasonic tumor imaging and targeted chemotherapy. J Natl Cancer Inst, 99(14), 1095-1106 (2007).

20. Schroeder A, Avnir Y, Weisman S et al. Controlling liposomal drug release with low frequency ultrasound: mechanism and feasibility. Langmuir, 23(7), 4019-4025 (2007).

21. Schroeder A, Kost J, Barenholz Y. Ultrasound, liposomes, and drug delivery: principles for using ultrasound to control the release of drugs from liposomes. Chem Phys Lipids, 162(1-2), 1-16 (2009).

22. Lide DR. Speed of Sound in Various Media. In: CRC Handbook of Chemistry and Physics, 84th Edition. (CRC Press, Boca Raton, Florida, 2003)

23. Goss SA, Frizzell LA, Dunn F. Ultrasonic absorption and attenuation in mammalian tissues. Ultrasound Med Biol, 5(2), 181-186 (1979).

24. Postema M. Fundamentals of Medical Ultrasonics (Spon Press, London, 2011).

25. Postema M, Gilja $\mathrm{OH}$. Contrast-enhanced and targeted ultrasound. World $J$ Gastroenterol, 17(1), 28-41 (2011).

26. Morgan KE, Allen JS, Dayton PA, Chomas JE, Klibaov AL, Ferrara KW. Experimental and theoretical evaluation of microbubble behavior: effect of transmitted phase and bubble size. IEEE Trans Ultrason Ferroelectr Freq Control, 47(6), 14941509 (2000).

27. Dayton PA, Morgan KE, Klibanov AL, Brandenburger GH, Ferrara KW. Optical and acoustical observations of the effects of ultrasound on contrast agents. IEEE Trans Ultrason Ferroelectr Freq Control, 46(1), 220-232 (1999).

* One of the first studies reporting the behavior of microbubbles under ultrasound exposure.

28. Wu J, Nyborg WL. Ultrasound, cavitation bubbles and their interaction with cells. $A d v$ Drug Deliv Rev, 60(10), 1103-1116 (2008).

29. Postema M, Kotopoulis S, Delalande A, Gilja OH. Sonoporation: why microbubbles create pores. Ultraschall in der Medizin, 33(1), 97-98 (2012).

30. Prentice P, Cuschierp A, Dholakia K, Prausnitz M, Campbell P. Membrane disruption by optically controlled microbubble cavitation. Nat. Phys., 1(2), 107-110 (2005).

* This study elegantly shows the pushing and pulling behaviour of a single microbubble next to a cell under ultrasound has been shown by high speed imaging.

31. van Wamel A, Kooiman $\mathrm{K}$, Harteveld $\mathrm{M}$ et al. Vibrating microbubbles poking individual cells: drug transfer into cells via sonoporation. J Control Release, 112(2), 149-155 (2006).

32. Duvshani-Eshet M, Machluf M. Therapeutic ultrasound optimization for gene delivery: a key factor achieving nuclear DNA localization. J Control Release, 108(23), 513-528 (2005).

33. Kaddur K, Lebegue L, Tranquart F, Midoux P, Pichon C, Bouakaz A. Transient transmembrane release of green fluorescent proteins with sonoporation. IEEE Trans Ultrason Ferroelectr Freq Control, 57(7), 1558-1567 (2010).

34. Mehier-Humbert S, Bettinger T, Yan F, Guy RH. Plasma membrane poration induced by ultrasound exposure: implication for drug delivery. J Control Release, 104(1), 213 222 (2005).

* This study demonstrates the membrane poration during sonoporation and its role for drug delivery. 
35. Mehier-Humbert S, Bettinger T, Yan F, Guy RH. Ultrasound-mediated gene delivery: kinetics of plasmid internalization and gene expression. J Control Release, 104(1),

45. Mukherjee D, Wong J, Griffin B et al. Ten-fold augmentation of endothelial uptake of vascular endothelial growth factor with ultrasound after systemic administration. $J \mathrm{Am}$ Coll Cardiol, 35(6), 1678-1686 (2000).

46. Taniyama $\mathrm{Y}$, Tachibana $\mathrm{K}$, Hiraoka $\mathrm{K}$ et al. Local delivery of plasmid DNA into rat carotid artery using ultrasound. Circulation, 105(10), 1233-1239 (2002).

47. Zhou Y, Kumon RE, Cui J, Deng CX. The Size of Sonoporation Pores on the Cell Membrane. Ultrasound Med Biol, (2009).

48. Deng CX, Sieling F, Pan H, Cui J. Ultrasound-induced cell membrane porosity. Ultrasound Med Biol, 30(4), 519-526 (2004).

49. Karshafian R, Bevan PD, Williams R, Samac S, Burns PN. Sonoporation by ultrasound-activated microbubble contrast agents: effect of acoustic exposure parameters on cell membrane permeability and cell viability. Ultrasound Med Biol, 35(5), 847-860 (2009).

50. Juffermans LJ, Meijering DB, van Wamel A et al. Ultrasound and microbubbletargeted delivery of therapeutic compounds: ICIN Report Project 49: Drug and gene delivery through ultrasound and microbubbles. Neth Heart J, 17(2), 82-86 (2009).

51. Fan Z, Kumon RE, Park J, Deng CX. Intracellular delivery and calcium transients generated in sonoporation facilitated by microbubbles. J Control Release, (2010). 
52. Kumon RE, Aehle M, Sabens D et al. Spatiotemporal effects of sonoporation measured by real-time calcium imaging. Ultrasound Med Biol, 35(3), 494-506 (2009).

53. Kumon RE, Aehle M, Sabens D, Parikh P, Kourennyi D, Deng CX. Ultrasoundinduced calcium oscillations and waves in Chinese hamster ovary cells in the presence of microbubbles. Biophys J, 93(6), L29-31 (2007).

54. Park J, Fan Z, Deng CX. Effects of shear stress cultivation on cell membrane disruption and intracellular calcium concentration in sonoporation of endothelial cells. J Biomech, 44(1), 164-169 (2011).

55. Paula DM, Valero-Lapchik VB, Paredes-Gamero EJ, Han SW. Therapeutic ultrasound promotes plasmid DNA uptake by clathrin-mediated endocytosis. J Gene Med, 13(78), 392-401 (2011).

56. Meijering BD, Juffermans LJ, van Wamel A et al. Ultrasound and microbubbletargeted delivery of macromolecules is regulated by induction of endocytosis and pore formation. Circ Res, 104(5), 679-687 (2009).

** This study presents the involvement of the endocytosis pathways and the cargo size during ultrasound and microbubble drug delivery.

57. Eliasson L, Proks P, Ammala $\mathrm{C}$ et al. Endocytosis of secretory granules in mouse pancreatic beta-cells evoked by transient elevation of cytosolic calcium. J Physiol, 493 ( Pt 3), 755-767 (1996).

58. MacDonald PE, Eliasson L, Rorsman P. Calcium increases endocytotic vesicle size and accelerates membrane fission in insulin-secreting INS-1 cells. J Cell Sci, $118(\mathrm{Pt}$ 24), 5911-5920 (2005).

59. Juffermans LJ, Dijkmans PA, Musters RJ, Visser CA, Kamp O. Transient permeabilization of cell membranes by ultrasound-exposed microbubbles is related to formation of hydrogen peroxide. Am J Physiol Heart Circ Physiol, 291(4), H15951601 (2006).

60. Bao S, Thrall BD, Miller DL. Transfection of a reporter plasmid into cultured cells by sonoporation in vitro. Ultrasound Med Biol, 23(6), 953-959 (1997).

61. Miller DL, Thomas RM, Frazier ME. Ultrasonic cavitation indirectly induces single strand breaks in DNA of viable cells in vitro by the action of residual hydrogen peroxide. Ultrasound Med Biol, 17(7), 729-735 (1991).

62. Juffermans LJ, Kamp O, Dijkmans PA, Visser CA, Musters RJ. Low-intensity ultrasound-exposed microbubbles provoke local hyperpolarization of the cell membrane via activation of $\mathrm{BK}(\mathrm{Ca})$ channels. Ultrasound Med Biol, 34(3), 502-508 (2008).

63. Tran TA, Le Guennec JY, Bougnoux P, Tranquart F, Bouakaz A. Characterization of cell membrane response to ultrasound activated microbubbles. IEEE Trans Ultrason Ferroelectr Freq Control, 55(1), 43-49 (2008).

64. Tran TA, Roger S, Le Guennec JY, Tranquart F, Bouakaz A. Effect of ultrasoundactivated microbubbles on the cell electrophysiological properties. Ultrasound Med. Biol., 33(1), 158-163 (2007).

65. Greenleaf WJ, Bolander ME, Sarkar G, Goldring MB, Greenleaf JF. Artificial cavitation nuclei significantly enhance acoustically induced cell transfection. Ultrasound Med Biol, 24(4), 587-595 (1998).

66. Stride E, Edirisinghe M. Novel preparation techniques for controlling microbubble uniformity: a comparison. Medical \& biological engineering \& computing, 47(8), 883-892 (2009). 
67. Zhao YZ, Liang HD, Mei XG, Halliwell M. Preparation, characterization and in vivo observation of phospholipid-based gas-filled microbubbles containing hirudin. Ultrasound Med Biol, 31(9), 1237-1243 (2005).

68. Huang SL. Liposomes in ultrasonic drug and gene delivery. Adv Drug Deliv Rev, 60(10), 1167-1176 (2008).

* An overview of echogenic liposomes preparation, their features with regards to lipids composition and their applications for drug and gene delivery.

69. Klibanov AL. Ligand-carrying gas-filled microbubbles: ultrasound contrast agents for targeted molecular imaging. Bioconjugate chemistry, 16(1), 9-17 (2005).

70. Aoi A, Watanabe Y, Mori S, Takahashi M, Vassaux G, Kodama T. Herpes simplex virus thymidine kinase-mediated suicide gene therapy using nano/microbubbles and ultrasound. Ultrasound Med Biol, 34(3), 425-434 (2008).

71. Lentacker I, Geers B, Demeester J, De Smedt SC, Sanders NN. Design and evaluation of doxorubicin-containing microbubbles for ultrasound-triggered doxorubicin delivery: cytotoxicity and mechanisms involved. Mol Ther, 18(1), 101-108 (2010).

72. Ibsen S, Benchimol M, Simberg D, Schutt C, Steiner J, Esener S. A novel nested liposome drug delivery vehicle capable of ultrasound triggered release of its payload. J Control Release, (2011).

73. Lee H, Pastor RW. Coarse-grained model for PEGylated lipids: effect of PEGylation on the size and shape of self-assembled structures. J Phys Chem B, 115(24), 78307837 (2011).

74. Suzuki R, Takizawa T, Negishi Y, Utoguchi N, Maruyama K. Effective gene delivery with liposomal bubbles and ultrasound as novel non-viral system. Journal of drug targeting, 15(7-8), 531-537 (2007).

75. Un K, Kawakami S, Suzuki R, Maruyama K, Yamashita F, Hashida M. Development of an ultrasound-responsive and mannose-modified gene carrier for DNA vaccine therapy. Biomaterials, 31(30), 7813-7826 (2010).

76. Kheirolomoom A, Dayton PA, Lum AF et al. Acoustically-active microbubbles conjugated to liposomes: characterization of a proposed drug delivery vehicle. $J$ Control Release, 118(3), 275-284 (2007).

77. Klibanov AL. Ultrasound molecular imaging with targeted microbubble contrast agents. J Nucl Cardiol, 14(6), 876-884 (2007).

78. Lindner JR, Song J, Christiansen J, Klibanov AL, Xu F, Ley K. Ultrasound assessment of inflammation and renal tissue injury with microbubbles targeted to Pselectin. Circulation, 104(17), 2107-2112 (2001).

79. Anderson CR, Rychak JJ, Backer M, Backer J, Ley K, Klibanov AL. scVEGF microbubble ultrasound contrast agents: a novel probe for ultrasound molecular imaging of tumor angiogenesis. Invest Radiol, 45(10), 579-585 (2010).

80. Anwer K, Kao G, Proctor B et al. Ultrasound enhancement of cationic lipid-mediated gene transfer to primary tumors following systemic administration. Gene Ther, 7(21), 1833-1839 (2000).

81. Vannan M, McCreery $\mathrm{T}$, Li $\mathrm{P}$ et al. Ultrasound-mediated transfection of canine myocardium by intravenous administration of cationic microbubble-linked plasmid DNA. J Am Soc Echocardiogr, 15(3), 214-218 (2002).

82. Christiansen JP, French BA, Klibanov AL, Kaul S, Lindner JR. Targeted tissue transfection with ultrasound destruction of plasmid-bearing cationic microbubbles. Ultrasound Med Biol, 29(12), 1759-1767 (2003). 
83. Hayashi S, Mizuno M, Yoshida J, Nakao A. Effect of sonoporation on cationic liposome-mediated IFNbeta gene therapy for metastatic hepatic tumors of murine colon cancer. Cancer gene therapy, 16(8), 638-643 (2009).

84. Tlaxca JL, Anderson CR, Klibanov AL et al. Analysis of in vitro transfection by sonoporation using cationic and neutral microbubbles. Ultrasound Med Biol, 36(11), 1907-1918 (2010).

85. Lentacker I, De Geest BG, Vandenbroucke RE et al. Ultrasound-responsive polymercoated microbubbles that bind and protect DNA. Langmuir, 22(17), 7273-7278 (2006).

86. Borden MA, Caskey CF, Little E, Gillies RJ, Ferrara KW. DNA and polylysine adsorption and multilayer construction onto cationic lipid-coated microbubbles. Langmuir, 23(18), 9401-9408 (2007).

87. Vandenbroucke RE, Lentacker I, Demeester J, De Smedt SC, Sanders NN. Ultrasound assisted siRNA delivery using PEG-siPlex loaded microbubbles. J Control Release, 126(3), 265-273 (2008).

88. Sirsi SR, Hernandez SL, Zielinski L et al. Polyplex-microbubble hybrids for ultrasound-guided plasmid DNA delivery to solid tumors. J Control Release, 157(2), 224-234 (2012).

89. Suzuki R, Maruyama K. Effective in vitro and in vivo gene delivery by the combination of liposomal bubbles (bubble liposomes) and ultrasound exposure. Methods in molecular biology (Clifton, N.J, 605, 473-486 (2010).

* : Protocols for the development and applications of custom gas-filled bubbles liposomes for gene delivery.

90. Suzuki R, Takizawa T, Negishi Y et al. Gene delivery by combination of novel liposomal bubbles with perfluoropropane and ultrasound. J Control Release, 117(1), 130-136 (2007).

91. Suzuki R, Takizawa T, Negishi Y, Utoguchi N, Maruyama K. Effective gene delivery with novel liposomal bubbles and ultrasonic destruction technology. Int $J$ Pharm, 354(1-2), 49-55 (2008).

92. Suzuki R, Namai E, Oda Y et al. Cancer gene therapy by IL-12 gene delivery using liposomal bubbles and tumoral ultrasound exposure. J Control Release, 142(2), 245250 (2010).

93. Suzuki R, Takizawa T, Negishi Y et al. Tumor specific ultrasound enhanced gene transfer in vivo with novel liposomal bubbles. $J$ Control Release, 125(2), 137-144 (2008).

94. Newman CM, Bettinger T. Gene therapy progress and prospects: ultrasound for gene transfer. Gene Ther, 14(6), 465-475 (2007).

95. Pichon C, Kaddur K, Midoux P, Tranquart F, Bouakaz A. Recent advances in gene delivery with ultrasound and microbubbles. J. Exp. Nanosci., 3(1), 17-40 (2008).

96. Suzuki R, Oda Y, Utoguchi N, Maruyama K. Progress in the development of ultrasound-mediated gene delivery systems utilizing nano- and microbubbles. $J$ Control Release, 149(1), 36-41 (2011).

97. Haag P, Frauscher F, Gradl J et al. Microbubble-enhanced ultrasound to deliver an antisense oligodeoxynucleotide targeting the human androgen receptor into prostate tumours. J Steroid Biochem Mol Biol, 102(1-5), 103-113 (2006).

98. Kim HJ, Greenleaf JF, Kinnick RR, Bronk JT, Bolander ME. Ultrasound-mediated transfection of mammalian cells. Hum. Gene Ther., 7(11), 1339-1346 (1996). 
99. Huber PE, Pfisterer P. In vitro and in vivo transfection of plasmid DNA in the Dunning prostate tumor R3327-AT1 is enhanced by focused ultrasound. Gene Ther, 7(17), 1516-1525 (2000).

100. Huber PE, Mann MJ, Melo LG et al. Focused ultrasound (HIFU) induces localized enhancement of reporter gene expression in rabbit carotid artery. Gene Ther, 10(18), 1600-1607 (2003).

101. Li T, Tachibana K, Kuroki M. Gene transfer with echo-enhanced contrast agents: comparison between Albunex, Optison, and Levovist in mice--initial results. Radiology, 229(2), 423-428 (2003).

102. Chen S, Shohet RV, Bekeredjian R, Frenkel P, Grayburn PA. Optimization of ultrasound parameters for cardiac gene delivery of adenoviral or plasmid deoxyribonucleic acid by ultrasound-targeted microbubble destruction. $\mathrm{J}$ Am Coll Cardiol, 42(2), 301-308 (2003).

103. Bekeredjian R, Chen S, Frenkel PA, Grayburn PA, Shohet RV. Ultrasound-targeted microbubble destruction can repeatedly direct highly specific plasmid expression to the heart. Circulation, 108(8), 1022-1026 (2003).

104. Kondo I, Ohmori K, Oshita A et al. Treatment of acute myocardial infarction by hepatocyte growth factor gene transfer: the first demonstration of myocardial transfer of a "functional" gene using ultrasonic microbubble destruction. J Am Coll Cardiol, 44(3), 644-653 (2004).

105. Leong-Poi H, Kuliszewski MA, Lekas $\mathrm{M}$ et al. Therapeutic arteriogenesis by ultrasound-mediated VEGF165 plasmid gene delivery to chronically ischemic skeletal muscle. Circ Res, 101(3), 295-303 (2007).

106. Kobulnik J, Kuliszewski MA, Stewart DJ, Lindner JR, Leong-Poi H. Comparison of gene delivery techniques for therapeutic angiogenesis ultrasound-mediated destruction of carrier microbubbles versus direct intramuscular injection. J Am Coll Cardiol, 54(18), 1735-1742 (2009).

107. Fujii H, Sun Z, Li SH et al. Ultrasound-targeted gene delivery induces angiogenesis after a myocardial infarction in mice. JACC Cardiovasc Imaging, 2(7), 869-879 (2009).

108. Fujii $\mathrm{H}, \mathrm{Li} \mathrm{SH}, \mathrm{Wu} \mathrm{J}$ et al. Repeated and targeted transfer of angiogenic plasmids into the infarcted rat heart via ultrasound targeted microbubble destruction enhances cardiac repair. Eur Heart J, 32(16), 2075-2084 (2011).

109. Reddi AH. Role of morphogenetic proteins in skeletal tissue engineering and regeneration. Nature biotechnology, 16(3), 247-252 (1998).

110. Nakashima M, Tachibana K, Iohara K, Ito M, Ishikawa M, Akamine A. Induction of reparative dentin formation by ultrasound-mediated gene delivery of growth/differentiation factor 11. Hum Gene Ther, 14(6), 591-597 (2003).

111. Sheyn D, Kimelman-Bleich N, Pelled G, Zilberman Y, Gazit D, Gazit Z. Ultrasoundbased nonviral gene delivery induces bone formation in vivo. Gene Ther, (2007).

112. Yang RS, Lin WL, Chen YZ et al. Regulation by ultrasound treatment on the integrin expression and differentiation of osteoblasts. Bone, 36(2), 276-283 (2005).

113. Osawa K, Okubo Y, Nakao K, Koyama N, Bessho K. Osteoinduction by microbubbleenhanced transcutaneous sonoporation of human bone morphogenetic protein-2. $J$ Gene Med, 11(7), 633-641 (2009).

114. Katagiri $\mathrm{T}$, Yamaguchi A, Ikeda $\mathrm{T}$ et al. The non-osteogenic mouse pluripotent cell line, $\mathrm{C} 3 \mathrm{H} 10 \mathrm{~T} 1 / 2$, is induced to differentiate into osteoblastic cells by recombinant human bone morphogenetic protein-2. Biochem Biophys Res Commun, 172(1), 295 299 (1990). 
115. Andersson GB. Epidemiological features of chronic low-back pain. Lancet, 354(9178), 581-585 (1999).

116. Freemont AJ, Peacock TE, Goupille P, Hoyland JA, O'Brien J, Jayson MI. Nerve ingrowth into diseased intervertebral disc in chronic back pain. Lancet, 350(9072), 178-181 (1997).

117. Nishida K, Doita M, Takada $\mathrm{T}$ et al. Sustained transgene expression in intervertebral disc cells in vivo mediated by microbubble-enhanced ultrasound gene therapy. Spine (Phila Pa 1976), 31(13), 1415-1419 (2006).

118. Suzuki T, Nishida K, Kakutani K et al. Sustained long-term RNA interference in nucleus pulposus cells in vivo mediated by unmodified small interfering RNA. Eur Spine J, 18(2), 263-270 (2009).

119. Delalande A, Bouakaz A, Renault G et al. Ultrasound and microbubble-assisted gene delivery in Achilles tendons: Long lasting gene expression and restoration of fibromodulin KO phenotype. J Control Release, 156(2), 223-230 (2011).

120. Delalande A, Bureau MF, Midoux P, Bouakaz A, Pichon C. Ultrasound-assisted microbubbles gene transfer in tendons for gene therapy. Ultrasonics, 50(2), 269-272 (2010).

121. Lou J. In vivo gene transfer into tendon by recombinant adenovirus. Clin Orthop Relat Res, (379 Suppl), S252-255 (2000).

122. Duvshani-Eshet M, Benny O, Morgenstern A, Machluf M. Therapeutic ultrasound facilitates antiangiogenic gene delivery and inhibits prostate tumor growth. Mol Cancer Ther, 6(8), 2371-2382 (2007).

123. Duvshani-Eshet M, Machluf M. Efficient transfection of tumors facilitated by longterm therapeutic ultrasound in combination with contrast agent: from in vitro to in vivo setting. Cancer gene therapy, 14(3), 306-315 (2007).

124. Collins CG, Tangney M, Larkin JO et al. Local gene therapy of solid tumors with GM-CSF and B7-1 eradicates both treated and distal tumors. Cancer gene therapy, 13(12), 1061-1071 (2006).

125. Craig R, Cutrera J, Zhu S, Xia X, Lee YH, Li S. Administering plasmid DNA encoding tumor vessel-anchored IFN-alpha for localizing gene product within or into tumors. Mol Ther, 16(5), 901-906 (2008).

126. Hauff P, Seemann S, Reszka R et al. Evaluation of gas-filled microparticles and sonoporation as gene delivery system: feasibility study in rodent tumor models. Radiology, 236(2), 572-578 (2005).

127. Iwanaga $\mathrm{K}$, Tominaga $\mathrm{K}$, Yamamoto $\mathrm{K}$ et al. Local delivery system of cytotoxic agents to tumors by focused sonoporation. Cancer gene therapy, 14(4), 354-363 (2007).

128. Li YS, Davidson E, Reid CN, McHale AP. Optimising ultrasound-mediated gene transfer (sonoporation) in vitro and prolonged expression of a transgene in vivo: potential applications for gene therapy of cancer. Cancer Lett, 273(1), 62-69 (2009).

129. Sato M, O'Gara P, Harding SE, Fuller SJ. Enhancement of adenoviral gene transfer to adult rat cardiomyocytes in vivo by immobilization and ultrasound treatment of the heart. Gene Ther, 12(11), 936-941 (2005).

130. Howard CM, Forsberg F, Minimo C, Liu JB, Merton DA, Claudio PP. Ultrasound guided site specific gene delivery system using adenoviral vectors and commercial ultrasound contrast agents. Journal of cellular physiology, 209(2), 413-421 (2006).

131. Guo Z, Hong S, Jin X, Luo Q, Wang Z, Wang Y. Study on the multidrug resistance 1 gene transfection efficiency using adenovirus vector enhanced by ultrasonic microbubbles in vitro. Mol Biotechnol, 48(2), 138-146 (2011). 
132. Muller OJ, Schinkel S, Kleinschmidt JA, Katus HA, Bekeredjian R. Augmentation of AAV-mediated cardiac gene transfer after systemic administration in adult rats. Gene Ther, 15(23), 1558-1565 (2008).

133. Bekeredjian R, Chen S, Pan W, Grayburn PA, Shohet RV. Effects of ultrasoundtargeted microbubble destruction on cardiac gene expression. Ultrasound Med Biol, 30(4), 539-543 (2004).

134. Chen S, Kroll MH, Shohet RV, Frenkel P, Mayer SA, Grayburn PA. Bioeffects of myocardial contrast microbubble destruction by echocardiography. Echocardiography, 19(6), 495-500 (2002).

135. Martin KR, Klein RL, Quigley HA. Gene delivery to the eye using adeno-associated viral vectors. Methods (San Diego, Calif, 28(2), 267-275 (2002).

136. Negrete A, Kotin RM. Strategies for manufacturing recombinant adeno-associated virus vectors for gene therapy applications exploiting baculovirus technology. Brief Funct Genomic Proteomic, 7(4), 303-311 (2008).

137. Touchard E, Kowalczuk L, Bloquel C, Naud MC, Bigey P, Behar-Cohen F. The ciliary smooth muscle electrotransfer: basic principles and potential for sustained intraocular production of therapeutic proteins. J Gene Med, 12(11), 904-919 (2010).

138. Xie W, Liu S, Su H, Wang Z, Zheng Y, Fu Y. Ultrasound microbubbles enhance recombinant adeno-associated virus vector delivery to retinal ganglion cells in vivo. Acad Radiol, 17(10), 1242-1248 (2010).

139. Levin LA, Schlamp CL, Spieldoch RL, Geszvain KM, Nickells RW. Identification of the bcl-2 family of genes in the rat retina. Invest Ophthalmol Vis Sci, 38(12), 25452553 (1997).

140. Dang SP, Wang RX, Qin MD et al. A novel transfection method for eukaryotic cells using polyethylenimine coated albumin microbubbles. Plasmid, 66(1), 19-25 (2011).

141. Deshpande MC, Prausnitz MR. Synergistic effect of ultrasound and PEI on DNA transfection in vitro. J Control Release, 118(1), 126-135 (2007).

142. Qiu Y, Luo Y, Zhang Y et al. The correlation between acoustic cavitation and sonoporation involved in ultrasound-mediated DNA transfection with polyethylenimine (PEI) in vitro. J Control Release, 145(1), 40-48 (2010).

143. Chen ZY, Liang K, Qiu RX. Targeted gene delivery in tumor xenografts by the combination of ultrasound-targeted microbubble destruction and polyethylenimine to inhibit survivin gene expression and induce apoptosis. J Exp Clin Cancer Res, 29, 152 (2010).

144. Lu QL, Liang HD, Partridge T, Blomley MJ. Microbubble ultrasound improves the efficiency of gene transduction in skeletal muscle in vivo with reduced tissue damage. Gene Ther, 10(5), 396-405 (2003).

145. Xenariou S, Griesenbach U, Liang HD et al. Use of ultrasound to enhance nonviral lung gene transfer in vivo. Gene Ther, 14(9), 768-774 (2007).

146. ter Haar G, Shaw A, Pye S et al. Guidance on reporting ultrasound exposure conditions for bio-effects studies. Ultrasound Med Biol, 37(2), 177-183 (2011).

* * In this paper, authors gave a set of recommendation as guidelines to evaluate US bioeffects for researchers who are working on therapeutic ultrasound.

147. Pichon C, Billiet L, Midoux P. Chemical vectors for gene delivery: uptake and intracellular trafficking. Current opinion in biotechnology, 21(5), 640-645 (2010).

148. Harraghy N, Gaussin A, Mermod N. Sustained transgene expression using MAR elements. Current gene therapy, 8(5), 353-366 (2008).

149. Glover DJ, Lipps HJ, Jans DA. Towards safe, non-viral therapeutic gene expression in humans. Nature reviews, 6(4), 299-310 (2005). 
1100 150. Kinoshita M, Hynynen K. Key factors that affect sonoporation efficiency in in vitro settings: the importance of standing wave in sonoporation. Biochem Biophys Res Commun. 359(4):860-865 (2007)

1103

1104

1105 